\title{
Collagen-based wound dressings for the treatment of diabetes-related foot ulcers: a systematic review
}

This article was published in the following Dove Press journal: Diabetes, Metabolic Syndrome and Obesity:Targets and Therapy 18 January 2013

Number of times this article has been viewed

\author{
Crystal Holmes' \\ James S Wrobel' \\ Mark P MacEachern ${ }^{2}$ \\ Blaise R Boles ${ }^{3}$ \\ 'Department of Internal Medicine, \\ University of Michigan Medical School, \\ ${ }^{2}$ A Alfred Taubman Health Sciences \\ Library, University of Michigan, \\ ${ }^{3}$ Department of Molecular, Cellular, \\ and Developmental Biology, University \\ of Michigan, Ann Arbor, MI, USA
}

Background: Diabetic foot ulcers are a major source of morbidity, limb loss, and mortality. A prolonged inflammatory response, extracellular matrix degradation irregularities, and increased bacteria presence have all been hypothesized as major contributing factors in the delayed healing of diabetic wounds. Collagen components such as fibroblast and keratinocytes are fundamental to the process of wound healing and skin formation. Wound dressings that contain collagen products create a biological scaffold matrix that supports the regulation of extracellular components and promotes wound healing.

Methods: A systematic review of studies reporting collagen wound dressings used in the treatment of Diabetic foot ulcers was conducted. Comprehensive searches were run in Ovid MEDLINE, PubMed, EMBASE, and ISI Web of Science to capture citations pertaining to the use of collagen wound dressings in the treatment of diabetic foot ulcers. The searches were limited to human studies reported in English.

Results: Using our search strategy, 26 papers were discussed, and included 13 randomized designs, twelve prospective cohorts, and one retrospective cohort, representing 2386 patients with diabetic foot ulcers. Our design was not a formal meta-analysis. In those studies where complete epithelialization, $58 \%$ of collagen-treated wounds completely healed (weighted mean $67 \%$ ). Only $23 \%$ of studies reported control group healing with $29 \%$ healing (weighted mean $11 \%$ ) described for controls.

Conclusion: Collagen- based wound dressings can be an effective tool in the healing of diabetic foot wounds. The current studies show an overall increase in healing rates despite limitations in study designs. This study suggests that future works focus on biofilms and extracellular regulation, and include high risk patients.

Keywords: bio films, matrix, wound healing, scaffold, dressings

\section{Introduction}

Collagen-containing wound dressings have been used in the treatment of diabetesrelated foot ulcers (DFU). Collagen components, such as fibroblast and keratinocytes, are a major part of skin development. Collagen may be harvested from a variety of sources including living and nonliving bovine, porcine, and equine skin. Once harvested (via a proprietary process), a native collagen bioscaffold matrix is created that stabilizes the vascular and cellar components, which become incorporated into the wound bed. ${ }^{1}$ Preliminary findings suggest that collagen-containing wound dressings may have several advantageous features. Cullen et $\mathrm{al}^{2}$ reported the findings from the testing of an oxygenized regenerated cellulose (ORC)/collagen dressing. After use of the ORC/collagen dressing, researchers analyzed wound fluid and found a significant 
decrease in collagenase-like activity; gelatinase, matrix metalloproteinase (MMP)-2, and MMP-9 levels; and increased scavenged free radicals and binding of growth factors.

Failure of DFUs to heal can be the result of several factors. Normal wound healing maintains a balance of extracellular matrix degradation and formation. Nonhealing diabetic foot wounds maintain a chronic inflammatory state with lack of extracellular matrix formation. ${ }^{2}$ Bacteria are believed to play a role in chronic extracellular matrix degradation. Analysis of wound fluid has found increased levels of proteases, inflammatory cytokines, and decreased growth factors. ${ }^{3}$ In large cohort studies, the rate of clinically infected DFUs ranged from $58 \%-61 \%$.,5 One potential problem in treating DFUs with collagen-based dressings is some bacteria's known affinity for collagen. Many grampositive pathogens commonly found in diabetic foot ulcers, such as Staphylococcus aureus, Enterococcus faecalis, and Streptococcus equi, are able to bind to collagen by utilizing collagen-binding adhesins of the microbial surface component recognizing adhesive matrix molecules family. ${ }^{6-8}$ The collagen-binding microbial surface component recognizing adhesive matrix molecules on $S$. aureus is called CNA and is the prototype member of this family. CNA participates in the infectious process of pathogenic $S$. aureus and is shown to be a virulence factor in many different animal models of staphylococcal infections including arthritis, endocarditis, osteomyelitis, mastitis, and keratitis, ${ }^{6,9-13}$ suggesting that the ability to interact with collagen provides a general advantage to the bacteria in pathogenesis. At this time it is unclear whether these bacteria interact with collagen dressings and if so, what effect this has on wound healing.

Therefore, the purpose of this systematic review was to discuss the randomized clinical trials of DFUs and discuss future targets for improvement.

\section{Methods}

A health sciences librarian (MPM) performed searches in Ovid MEDLINE, PubMed, EMBASE, and ISI Web of Science to capture citations pertaining to the use of collagen wound dressings in the treatment of diabetic foot ulcers. The initial strategy was constructed in Ovid MEDLINE and then adapted to the other databases (see Figure 1 for the complete Ovid MEDLINE strategy). In all databases, with the exception of ISI Web of Science, a combination of controlled terms (Medical Subject Headings for Ovid MEDLINE and PubMed, and Elsevier's Life Sciences Thesaurus terms for EMBASE) and text words were used. Because the Web of

\begin{tabular}{|c|c|}
\hline 1 & Exp collagen/ \\
\hline 2 & Collagen*.mp \\
\hline 3 & Exp biological dressings/ \\
\hline 4 & Exp occlusive dressings/ \\
\hline 5 & or/1-4 \\
\hline 6 & Exp diabetic foot/ \\
\hline 7 & diabetic foot.tw \\
\hline 8 & 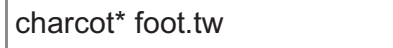 \\
\hline 9 & or/6-8 \\
\hline 10 & Exp foot diseases/ \\
\hline 11 & foot ulcer*.tw \\
\hline 12 & or/10-11 \\
\hline 13 & Exp diabetes mellitus/ \\
\hline 14 & diabet*.tw \\
\hline 15 & or/13-14 \\
\hline 16 & 12 and 15 \\
\hline 17 & 9 or 16 \\
\hline 18 & 5 and 17 \\
\hline 19 & Limit 18 to english language \\
\hline 20 & Limit 19 to animals \\
\hline 21 & Limit 19 to humans \\
\hline 22 & 19 not $(20$ not 21$)$ \\
\hline
\end{tabular}

Figure I Ovid MEDLINE search.

Science database does not have a controlled vocabulary, its search was comprised solely of text words. The searches were run in early May 2012, with English language and the exclusion of animal studies as the only limits applied at the time of the searches. A set of five sentinel articles identified by two of the authors (CMH, JSW) were used to validate the searches in each database. The search was designed to identify papers that (a) specifically used "collagen" in their titles and/or abstracts, or (b) were indexed with corresponding Medical Subject Headings or Elsevier's Life 
Sciences Thesaurus terms. Articles that did not meet these criteria may have been missed. In total, the searches returned 674 citations, 208 of which were identified as duplicates by the citation management program Endnote X4. The study librarian distributed the Endnote library and an Excel spreadsheet of the 466 unique citations to the authors involved in the article review (CMH, JSW, BRB).

Using the above search strategy, 466 papers were reviewed. Papers were considered for inclusion if they were published in English, were human studies, enrolled DFU patients, and used a collagen-based dressing. Cohort studies were also included in response to current recommended strategies for systematic reviews of wound healing. ${ }^{14} \mathrm{We}$ also expanded our review to include any discussion of any wound care product that contained collagen (as opposed to being exclusively constructed of collagen). ${ }^{15,16}$ Using these criteria, 49 papers were selected for review. There were eight papers with discordant reviews using all four criteria. The authors (CMH and JSW) adjudicated these papers using a modified Delphi approach. One additional paper was added for discussion after the adjudication process, resulting in 42 papers available for discussion.

Using the criteria proposed by Gottrup and colleagues, ${ }^{17}$ we discussed the remaining papers if they at least reported outcomes of $100 \%$ epithelialization, $50 \%$ healing, or $100 \%$ granulation tissue base. Of the 42 remaining papers, 16 did not provide enough detail to meet these criteria. Therefore, 26 papers were discussed.

\section{Results}

Table 1 depicts the studies included for discussion with their sample size, study design, and wound dressing treatment exposure. Using our search strategy, 26 papers were discussed and included 13 randomized designs, twelve prospective cohorts, and one retrospective cohort, representing 2386 patients with DFU. Our design was not a formal meta-analysis. There was great deal of heterogeneity in study designs, durations of study, patient populations, and acuity of wounds. Fewer than half of the studies described offloading well enough to assess if they met the offloading criteria and adherence standards proposed by Boulton and Armstrong; ${ }^{18}$ of these, only one met their criteria and this had no control group. In the studies that reported complete epithelialization, $58 \%$ of collagen-treated wounds completely healed (weighted mean $67 \%$ ). Only $23 \%$ of studies reported control group healing, with 29\% healing (weighted mean 11\%) described for controls; this weighted mean was below the $24 \%$ reported in a meta-analysis of control group healing for DFU. ${ }^{19}$ In the four papers that described wound healing rate, this ranged from 30-84 days.

\section{Discussion}

\section{Bioengineered tissues:Apligraf ${ }^{\circledR}$}

Several studies have described the use of Apligraf (Organogenesis Inc, Canton, MA) for treatment of DFU. ${ }^{20-23}$ Apligraf is a living bioengineered dressing that is bilayered, with cultured keratinocytes placed on the surface of a fibroblast-populated lattice made from type 1 bovine collagen. Edmonds ${ }^{21}$ studied 82 DFU patients with wounds present for at least 2 weeks. Following a 2-week screening period, patients were randomized to either a treatment group receiving Apligraf or a control group receiving sharp debridement, non-weight-bearing activity, and saline wet-to-dry dressings. At 12 weeks, $51.5 \%$ of Apligraf-treated patients were healed versus $26.3 \%$ of controls, and $12 \%$ of patients were lost to follow-up. ${ }^{21}$ Brem and colleagues ${ }^{20,24}$ also studied Apligraf in patients with DFU. In a prospective cohort study, eleven nonischemic DFU patients with 13 DFUs were followed until they were fully healed. All patients healed with an average healing time of 32 days \pm 12 days. ${ }^{24}$ Brem and colleagues also studied a cohort of DFU patients with more complicated wounds. Two of the wounds extended to bone, and four patients had active infection. There were also four patients that had ischemia that would likely exclude them from randomized trials (based on ankle brachial indices in two patients, and gangrene in the other two). In this more complex population, $86 \%$ of wounds were healed by 6 months. ${ }^{20}$ Sams and colleagues ${ }^{22}$ conducted a randomized controlled trial of 17 patients with nonhealing DFUs. In this study, 20 patients went through a 1 -week screening process following debridement, offloading, and saline wet-to-dry dressings. Patients were excluded if they showed $>30 \%$ healing or did not meet inclusion criteria, or if they had exclusion criteria. Patients were permitted up to five applications of Apligraf. After 12 weeks, 56\% of Apligraf-treated patients were healed and $38 \%$ of controls were healed. Veves and colleagues ${ }^{23}$ reported the pivotal trial of Apligraf that led to its FDA approval for the treatment of DFU. They studied 208 DFU patients for 12 weeks in 24 centers. All enrolled patients had a history of DFU for at least 2 weeks and completed a 7-day screening period of debridement, saline wet-to-dry dressings, and offloading where their ulcer did not heal by greater than $30 \%$. Patients were instructed to remain nonweight-bearing (with use of crutches or a wheelchair) for 6 
Table I Review of study design and results

\begin{tabular}{|c|c|c|c|c|c|c|c|c|}
\hline Author & $\begin{array}{l}\text { Total } \\
\mathbf{n}\end{array}$ & $\begin{array}{l}\text { \# diabetic } \\
\text { foot ulcers }\end{array}$ & $\begin{array}{l}\text { \# lost to } \\
\text { follow up }\end{array}$ & $\begin{array}{l}\% \text { lost to } \\
\text { follow up }\end{array}$ & $\begin{array}{l}\text { Study } \\
\text { design }\end{array}$ & $\begin{array}{l}\text { Duration } \\
\text { (weeks) }\end{array}$ & $\begin{array}{l}100 \% \\
\text { epithelialization I }\end{array}$ & $\begin{array}{l}50 \% \\
\text { reduction } \\
\text { in size } \\
\end{array}$ \\
\hline Edmonds $\mathrm{M}^{21}$ & 82 & 82 & 10 & $12 \%$ & RCT & 12 & $52 \%$ & \\
\hline Brem H et $\mathrm{al}^{24}$ & II & 11 & 0 & $0 \%$ & Cohort & & $100 \%$ & \\
\hline Brem H et $\mathrm{al}^{20}$ & 23 & 10 & 0 & $0 \%$ & Cohort & 26 & $70 \%$ & \\
\hline Gottrup $\mathrm{F}$ et $\mathrm{al}^{41}$ & 39 & 39 & 5 & $13 \%$ & $\mathrm{RCT}$ & 14 & $52 \%$ & $79 \%$ \\
\hline Ulrich $D$ et $\mathrm{al}^{42}$ & 32 & 32 & 0 & $0 \%$ & Cohort & & & Yes \\
\hline Fleischli JG et $\mathrm{a}^{33}$ & 32 & 32 & 2 & $6 \%$ & Cohort & 12 & $47 \%$ & $100 \%$ \\
\hline Donaghue VM et a ${ }^{143}$ & 75 & & 0 & $0 \%$ & RCT & 8 & $48 \%$ & \\
\hline Motzkau M et al $\left.\right|^{45}$ & 19 & & 0 & $0 \%$ & RCT & 26 days & $61 \%$ & \\
\hline Blume $\mathrm{P}$ et $\mathrm{al}^{48}$ & 113 & & 0 & $0 \%$ & RCT & 12 & $35 \%$ & \\
\hline Sams $\mathrm{HH}$ et $\mathrm{a}^{22}$ & 17 & 17 & I & $6 \%$ & RCT & 12 & $56 \%$ & \\
\hline Veves $\mathrm{A}$ et $\mathrm{al}^{23}$ & 208 & 208 & 0 & $0 \%$ & RCT & 12 & $56 \%$ & \\
\hline Marston WA et $\mathrm{al}^{47}$ & 6 & 6 & 0 & $0 \%$ & Cohort & 26 & $0 \%$ & \\
\hline Naughton $\mathrm{G}$ et $\mathrm{a}^{26}$ & 281 & 281 & 46 & $16 \%$ & $\mathrm{RCT}$ & 12 & $39 \%$ & \\
\hline Hamidi-Almadari ${ }^{49}$ & 8 & 8 & 0 & $0 \%$ & Cohort & 4 & $37 \%$ & \\
\hline Martin BR et $\mathrm{a}^{30}$ & 17 & 17 & 0 & $0 \%$ & Cohort & 20 & $84 \%$ & \\
\hline Kashefsky HE ${ }^{28}$ & 15 & 15 & I & $6 \%$ & Cohort & 12 & $100 \%$ & \\
\hline Letendere $\mathrm{S}$ et $\mathrm{al}^{74}$ & 13 & 14 & 1 & $7 \%$ & RCT & 12 & $55 \%$ & $33.3 \%$ \\
\hline Liao $\mathrm{HC}$ et $\mathrm{al}^{35}$ & 6 & 6 & 1 & $17 \%$ & Cohort & & $60 \%$ & \\
\hline Veves $A$ et $a^{46}$ & 276 & 276 & 0 & $0 \%$ & $\mathrm{RCT}$ & 12 & $37 \%$ & \\
\hline Lazaro-Martinez JL et a ${ }^{51}$ & 40 & 40 & 0 & $0 \%$ & $\begin{array}{l}\text { Retro-spective } \\
\text { cohort }\end{array}$ & 6 & $63 \%$ & \\
\hline Snyder RJ et $\mathrm{a}^{50}$ & 974 & 974 & 0 & $0 \%$ & Cohort & 8 & $95 \%$ & \\
\hline Ravari $\mathrm{H}$ et al ${ }^{49}$ & 8 & 8 & 0 & $0 \%$ & Cohort & 4 & $38 \%$ & $50 \%$ \\
\hline Mulder $\mathrm{G}$ et $\mathrm{a}^{75}$ & 15 & 15 & I & $6 \%$ & $\mathrm{RCT}$ & 12 & $67 \%$ & \\
\hline Clerici G et al ${ }^{34}$ & 30 & 30 & 0 & $0 \%$ & Cohort & & $87 \%$ & \\
\hline Brigido $\mathrm{SA}^{29}$ & 28 & 28 & 0 & $0 \%$ & RCT & 16 & $86 \%$ & \\
\hline Gentzkow GD et $\mathrm{a}^{27}$ & 50 & 50 & 0 & $0 \%$ & RCT & 12 & $50 \%$ & \\
\hline
\end{tabular}




\begin{tabular}{|c|c|c|c|c|c|c|c|c|}
\hline $\begin{array}{l}\text { Healing } \\
\text { time } \\
\text { (days) }\end{array}$ & $\begin{array}{l}100 \% \\
\text { epithelialization C }\end{array}$ & $\begin{array}{l}50 \% \\
\text { reduction } \\
\text { in size }\end{array}$ & $\begin{array}{l}100 \% \\
\text { granulation } \\
\text { tissue base }\end{array}$ & $\begin{array}{l}\text { Healing } \\
\text { time } \\
\text { (days) }\end{array}$ & $\begin{array}{l}\text { Standard } \\
\text { offloading }\end{array}$ & $\begin{array}{l}\text { Collagen } \\
\text { products }\end{array}$ & $\begin{array}{l}\text { Wound } \\
\text { classification }\end{array}$ & $\overline{\text { Blinding }}$ \\
\hline \multirow[t]{3}{*}{84} & $26 \%$ & & & & Not-weight & Apligraf ${ }^{\circledR}$ & ND & ND \\
\hline & & & & & bearing also has cast & & & \\
\hline & & & & & boot with orthoses & & & \\
\hline \multirow[t]{11}{*}{31} & & & & & ND & Apligraf ${ }^{\circledR}$ & ND & ND \\
\hline & & & & & Crutches, edu & Apligraf ${ }^{\circledR}$ & ND & ND \\
\hline & & $43 \%$ & $31 \%$ & & ND & ORC/collagen/silver & Wagner $2 / 3$ & ND \\
\hline & & & & & ND & ORC/collagen & ND & ND \\
\hline & & & & & $\begin{array}{l}\text { Cast boot } \\
\text { or sandal }\end{array}$ & Equine pericardium & ND & ND \\
\hline & $36 \%$ & & & & ND & $\begin{array}{l}\text { Fibracol }^{\circledR} \\
\text { (collagen alginate) }\end{array}$ & ND & ND \\
\hline & $0 \%$ & & & & ND & Promogran $^{\circledR}$ & UT $2 A$ & Single \\
\hline & & & & & & & & blinded \\
\hline & $31 \%$ & & & & DH walker ${ }^{T M}$ & Bovine collagen gel & Wagner I & Single \\
\hline & & & & & & & & blinded \\
\hline & $38 \%$ & & & & $\begin{array}{l}\text { Sandals, crutches, } \\
\text { wheelchair }\end{array}$ & Apligraf ${ }^{\circledR}$ & ND & ND \\
\hline \multirow[t]{20}{*}{65} & $38 \%$ & & & $\begin{array}{l}90 \text { days } \\
\text { median }\end{array}$ & $\begin{array}{l}\text { Sandals, crutches, } \\
\text { wheelchair }\end{array}$ & Apligraf $^{\circledR}$ & ND & ND \\
\hline & & & & & ND & Injected & Wagner I & ND \\
\hline & & & & & & porcine collagen & & \\
\hline & $32 \%$ & & & & Special shoes & Dermagraft $^{\circledR}$ & ND & Single \\
\hline & & & & & and inserts & & & blinded \\
\hline & & & & & & $\begin{array}{l}\text { Bone marrow- } \\
\text { impregnated collagen } \\
\text { matrix }\end{array}$ & ND & ND \\
\hline & & & & & & Graftjacket $^{\circledR}$ & UT grade $2 \mathrm{~A}$ & ND \\
\hline & & & & & TCC & Dermagraft ${ }^{\circledR}$ & Wagner grade $\mathrm{I} / 2$ & ND \\
\hline & & & & & ND & Biovance $^{T M}$ & Wagner grade I/2 & ND \\
\hline & & & & & & $\begin{array}{l}\text { Porcine graft-young } \\
\text { collagenous wettable } \\
\text { membrane }\end{array}$ & Not described & ND \\
\hline & & & & & $\begin{array}{l}\text { Offloading varied } \\
\text { per investigator }\end{array}$ & Promogran $^{\circledast}$ & Wagner grade $1 / 2$ & ND \\
\hline & & & & & & Promogran $^{\circledast}$ & Texas and & ND \\
\hline & & & & & & & Wagner & \\
\hline & & & & & & $\mathrm{C} / \mathrm{ORC} /$ silver and & ND & ND \\
\hline & & & & & & C/ORC (Prisma ${ }^{\circledR}$ & & \\
\hline & & & & & & and $\operatorname{Promogran}^{\circledR}$ ) & & \\
\hline & & & & & & Bone marrow- & ND & ND \\
\hline & & & & & & impregnated & & \\
\hline & & & & & & collagen matrix & & \\
\hline & & & & & Offloading shoe & GAM50I & ND & ND \\
\hline \multirow[t]{6}{*}{60} & & & & & Extra depth & Integra ${ }^{\circledR}$ & ND & ND \\
\hline & & & & & rocker shoe & & & \\
\hline & & & & & $\mathrm{TCC}$ & Graftjacket $^{\circledR}$ & ND & ND \\
\hline & & & & & Therapeutic & Dermagraft ${ }^{\circledR}$ & ND & Single \\
\hline & & & & & shoe/custom fitted & & & blinded \\
\hline & & & & & apex ambulator & & & \\
\hline
\end{tabular}


weeks, and were also given customized tridensity sandals. Apligraf patients were permitted up to five applications over a 5 week period, and received an average of 3.9 applications/ patient. At 12 weeks, $56 \%$ of Apligraf patients were healed $($ median $=66$ days $)$ and $38 \%$ (median $=90$ days $)$ of control patients were healed. There were no differences in infection rates, although the Apligraf group had significantly fewer cases of osteomyelitis and amputation. ${ }^{23}$ Steinberg and colleagues ${ }^{25}$ conducted a comparison between the Veves et al study ${ }^{23}$ and Edmonds study. ${ }^{21}$ Steinberg reported remarkable similarities between the European and US populations and use of similar methods. They found similar efficacy rates (of healing), recurrence rates, and safety profile.

\section{Bioengineered tissues: Dermagraft ${ }^{\circledR}$}

Dermagraft (Advanced Biohealing Inc, Westport, CT) was designed to replicate the dermis using a three-dimensional polymer scaffold of matrix proteins (including collagen types 1 and 3, fibronectin, and tenascin) with human diploid fibroblast cells throughout, cultured from neonatal foreskin. ${ }^{26}$

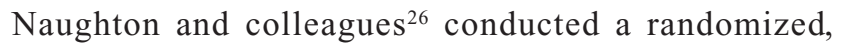
prospective, single-blinded study at 20 centers contributing 281 DFU patients. Of these, 235 patients were available for follow up with a higher (22\%) loss to follow up in the Dermagraft group. Rapid healers during the screening process were excluded, and controls were treated with debridement, and saline wet-to-dry dressings. It is noteworthy that offloading consisted of use of special shoes with inserts rather than use of crutches and wheelchairs for 6 weeks as seen in other studies. Researchers found that $38.5 \%$ of the Dermagraft group were healed versus $31.7 \%$ of the controls $(P=0.138)$. Patients receiving the metabolically active product for the entire (up to eight applications) trial went on to significantly higher rates of closure (54.1\%). Patients that received metabolically active product at their first application healed significantly (48.7\%) faster. A controlled, prospective, multicenter, randomized, single-blinded, pilot study was performed by Gentzkow et al. ${ }^{27}$ In this 12 -week study, 50 patients with DFU were randomized to four treatment groups: a control group, and three groups receiving identical care except for Dermagraft application. Offloading consisted of a therapeutic shoe. The results demonstrated that all groups with Dermagraft application had greater healing times and higher rates of $50 \%$ reduction in wound size. Weekly application of Dermagraft was also shown to have statistically significant higher wound healing rates than other Dermagraft application protocols. Kashefsky ${ }^{28}$ described the use of a combination of total contact cast and Dermagraft in 15 consecutive diabetic foot ulcer patients for a period of 12 weeks, or until fully healed. The results demonstrated an average healing rate of $23.7 \pm 16.3$ days. The average number of Dermagraft applications was 2.1. There was no correlation between ulcer duration or ulcer location (forefoot or midfoot), and time to healing; however, a correlation was found between wound size and healing time.

\section{Bioengineered tissues: Graftjacket ${ }^{\circledR}$}

Graftjacket (Kinetic Concepts Inc, San Antonio, TX) is an acellular dermal graft processed from human tissue. In the preparation of the product, the living tissue is removed and the matrix is left intact to serve as a scaffold for revascularization and host transplantation. In a 16-week randomized controlled study, 28 patients with DFU (Wagner grade 2) were placed in a control arm that received weekly sharp debridement or a treatment group that received weekly sharp debridement and Graftjacket. ${ }^{29}$ In this study, 14 patients were placed in each arm and no patients were lost to follow up. Offloading was not described. Complete wound closure was defined as complete epithelialization without drainage. After 14 weeks, 12 of the 14 patients with Graftjacket were healed compared to 4 of the 14 patients in the control arm. The average healing time in the Graftjacket-treatment group was 11.92 weeks vs 13.50 weeks in the control group. Statistical significance was noted in the final ulcer area, depth, volume, and number of ulcers healed with Graftjacket vs the control arm. Martin et $a^{30}$ described data from 17 consecutive patients who received surgical debridement for their diabetic foot wounds and were placed on therapy consisting of a single application of GraftJacket and weekly dressing changes. Offloading was not described. In the 20 -week evaluation period, $82.4 \%$ of wounds healed (healing was described as $100 \%$ epithelialization).

\section{Xenograft collagen dressings}

Landsman and colleagues ${ }^{31}$ described a study of 26 DFU patients who were randomized to receive up to three applications of Dermagraft or eight of Oasis ${ }^{\circledR}$ (Healthpoint Ltd, Fort Worth, TX), an extracellular collagen matrix derived for the submucosa of porcine small intestine. Patients received this treatment in addition to saline-moistened gauze dressings and were treated up to 12 weeks. There were no differences in the time or rate to closure between groups.

Other types of collagen matrix dressings incorporate scaffold features without active cellular components. Integra $^{\circledR}$ (Integra LifeSciences, Plainsboro, NJ) is one such product and is a porous matrix of bovine tendon collagen 
and glycosaminoglycan. Iorio and colleagues ${ }^{32}$ described their experience using Integra in a retrospective review of 80 admitted DFU patients undergoing limb salvage procedures. Following debridement, Integra was applied to the wound bed for up to 3 weeks in preparation of skin grafting. This approach resulted in a $46 \%$ limb salvage rate in the high-risk group. The authors concluded that this approach could be a new option for preventing limb loss and preventing morbidity in a select patient population. Other xenograft collagen dressings have been reported in the literature. Fleischli and colleagues ${ }^{33}$ studied equine pericardium applied to 23 patients with 34 DFUs present for at least 4 weeks. Following debridement, the graft was sutured in place and a below-knee compression wrap (with antibiotic ointment) was applied, and a cast boot or sandal was used for offloading. All patients in this prospective, cohort study realized $50 \%$ wound healing by 4 weeks; a further $47 \%$ went on to complete epithelialization after 12 weeks. Celerici and colleagues ${ }^{34}$ utilized Interga on diabetic foot wounds to preserve foot length at time of amputation. Of the 30 patients reviewed, $26(86.7 \%)$ showed healing of a distal amputation with an average healing time of $74 \pm 28.9$ days. Offloading was not described. None of the patients went on to a more proximal amputation. Porcine young collagen wettable membrane and growth factor was used in six patients with nonhealing wounds in a preliminary uncontrolled study by Liao et al. ${ }^{35}$ Offloading was not described. Five patients completed the study, and outcomes were described as healed or much improved with three of the five patients demonstrating an end result of healed. Mulder et $\mathrm{al}^{75}$ described the results from a Phase $1 / 2$ study of a replication-defective adenovirus encoding human platelet-derived growth factor (PDGF)-B formulated in a bovine collagen (Ad-5PDGF-B; 2.6\% collagen; GAM501) gel for nonhealing neuropathic diabetic foot ulcers. The primary objectives of the study were to evaluate the safety, maximum-tolerated dose, and preliminary biological activity of GAM501. Fifteen patients enrolled into the study with chronic, nonhealing ulcers. All patients were required to wear an off-loading shoe. In the 12 patients that completed the study, ulcer closure was observed by Month 3 in 10 patients. Per the authors report GAM501 did not appear to have any toxicity at doses that showed biological activity.

\section{Collagen dressings with silver}

Positively charged silver ions are highly reactive and affect multiple sites within bacterial cells. They bind to bacterial cell membranes, causing disruption of the bacterial cell wall and cell leakage, ultimately causing bacterial cell death. Silver ions are active against a broad range of bacteria including many antibiotic-resistant bacteria, such as methicillinresistant Staphylococcus aureus and vancomycin-resistant Enterococci. ${ }^{36}$ Effects of silver dressings on experimental models of biofilms have suggested that silver may reduce bacterial adhesion and destabilize the biofilm matrix ${ }^{37}$ as well as kill bacteria within the matrix and increase susceptibility of bacteria to antibiotics. ${ }^{38-40}$

Collagen dressings have also been described to have silver-containing product. Gottrup and colleagues ${ }^{41}$ described a randomized study examining the efficacy of collagen, ORC, and silver dressing for the treatment of DFU. Thirty-nine patients were randomized to either an ORC group or a control group and followed over 14 weeks. The control treatment consisted of a standardized treatment protocol. In the ORC group, $52 \%$ of patients demonstrated complete epithelialization with $79 \%$ demonstrating at least $50 \%$ closure after 4 weeks. In the control group, $31 \%$ of patients demonstrated complete epithelialization after 14 weeks with $43 \%$ demonstrating at least 50\% healing after 4 weeks, and the difference at 4 weeks was statistically significant. Patients in the ORC had no infections versus $31 \%$ of patients in the control group who had infections $(P=0.012)$. Ulrich and colleagues ${ }^{42}$ explored a potential mechanism of action for ORC dressings without silver in DFU patients. Thirty-two patients with DFU were studied and received either ORC $(\mathrm{n}=22)$ or hydrocolloid dressings $(n=10)$ Wound fluid was collected at days 0 and 5 , and every 2 weeks for the duration of study. Offloading was not described. Examination of the wound fluid suggested that ORC-treated DFUs had significantly less gelatinase, elastase, and plasmin in the wound and reductions in matrix metalloproteinase- 2 at weeks $2,4,6$, and 8 when compared with baseline. This group also demonstrated significantly greater wound size reduction at 2 and 4 weeks.

\section{Collagen dressings with alginate}

Alginate dressings are highly absorbent and come in the form of calcium alginate or calcium sodium alginate combined with collagen. The use of a collagen-based dressing in combination with alginate was described by Donaghue et al. ${ }^{43}$ In this study, 75 DFU patients were randomized in a 2:1 ratio to a treatment group receiving Fibracol ${ }^{\circledR}$ (Systagenix, Gatwick, UK) ( $90 \%$ collagen and $10 \%$ alginate) or a control group. The control treatment consisted of saline-moistened gauze and offloading consisting of felted foam total-contact dressing in a surgical sandal. At the end of 8 weeks, $48 \%$ of patients in the Fibracol-treated group were healed compared with $36 \%$ of the control group who were healed, and the difference was not significant. 


\section{Collagen dressings \\ with protease inhibitors}

Collagen dressings have also been combined with protease inhibitors. Two studies ${ }^{44,45}$ examined concentrations of MMPs in patients who received Promogran ${ }^{\circledR}$ (Systagenix), a protease inactivator modulating matrix-composed ORC and collagen. Lobmann and colleagues ${ }^{44}$ randomized 33 DFU patients to either a treatment group receiving daily Promogran dressings or a control group receiving "standard wound care." The wound care, debridement, and offloading strategies were not described. Central DFU punch biopsies were taken at baseline and after 4 and 8 days. Of the MMP measures, Interleukin- $1 \mathrm{~h}$ was increased on day 8 , and there was a significant reduction of the MMP-9/tissue inhibitors of metalloproteinases -2 ratio in the Promogran group. ${ }^{44}$ Motzkau and colleagues ${ }^{45}$ randomized 19 DFU patients to receive "good wound care" consisting of wound debridement and a dressing with a soft silicone contact layer, or Promogran with a soft silicone contact layer. Offloading was not described. Punch biopsies were taken at baseline and day 5. MMP-2 levels were significantly lower in the Promogran group, and $68 \%$ of patients in the Promogran group showed wound healing within 28 days versus none in the control group. The average starting wound size was smaller in the Promogran group than in the control group $\left(225 \mathrm{~mm}^{2}\right.$ vs $816 \mathrm{~mm},{ }^{2}$ respectively). ${ }^{45}$

When Promogran was compared to standard wound dressing, multivariate analysis indicated that Promogran was of marginally greater benefit, compared with salinemoistened gauze, in the treatment of diabetic foot ulcers with a duration of less than 6 months. ${ }^{46}$ In this randomized controlled trial by Veves et al, a total of 276 patients from eleven centers were enrolled in the study and randomized to receive either moistened gauze or Promogran. One hundred thirty-eight patients (50.0\%) patients were enrolled in each group, and all patients received study therapy according to their randomization. One hundred eighty-eight patients completed the study (104 in the Promogran group and 84 in the control group), and 98 of these 188 had ulcers that did not heal (53 in the Promogran group and 45 in the control group). Patients were stratified on the basis of the area of their target wound ( $<10$ or $\geq 10 \mathrm{~cm}^{2}$ ) before randomization. Offloading varied per investigator. By the 12-week measurements, 51 patients $(37.0 \%)$ in the Promogran and 39 patients $(28.3 \%)$ in the control group had achieved complete wound closure, and this difference was not statically significant
$(P=0.12)$. By week 12 , the mean percentage of reduction was similar in both groups: $64.5 \%$ in the Promogran group and $63.8 \%$ for the control group. The mean time to healing for those Promogran-treated patients with complete healing was $7.0 \pm 0.4$ weeks; in the control group this was $5.8 \pm 0.4$ weeks. ${ }^{46}$

\section{Collagen gel}

Marston and colleagues ${ }^{47}$ described the initial pilot study of a porcine-derived collagen injectable matrix scaffolding composed of gelatin (E-Matrix; ${ }^{\text {TM }}$ Encelle Inc, Greenville, NC). Six patients with DFU of greater than 2 months duration had their skin tested for allergy with forearm injections one week prior to DFU injection. DFU injection was performed on the periphery, deep to the ulcer, with volumes ranging from 1.3-9.4 mL. The average decrease in wound size was $72 \%$ after 2 weeks of hydrogel dressing with progress slowing after 4 weeks. Two wounds markedly improved after reinjection. No description of offloading was provided. Blume and colleagues ${ }^{48}$ described a phase 2 clinical trial of 113 per protocol DFU patients randomized to receive $2.6 \%$ formulated bovine collagen gel or $2.6 \%$ formulated bovine collagen gel with platelet derived growth factor B or a control treatment consisting of daily dressing changes. All patients used a DH Walker ${ }^{\mathrm{TM}}$ (Össur, Reykjavik, Iceland) for offloading and had a 2 week run-in period (healed $<30 \%$ ) of control care. At 12 weeks, there were no statistical differences between healing in the control group (31\%), in the group receiving $2.6 \%$ formulated bovine collagen gel (35\%), or in the group receiving $2.6 \%$ formulated bovine collagen gel with platelet derived growth factor B (41\%).

\section{Bone marrow impregnated collagen matrix}

Bone marrow has multipotential progenitor cells and produces growth factors. Impregnated autogenous bone marrow cells placed on a collagen matrix and applied topically to wounds has been suggested to increase the angiogenic effect and wound healing. Ravari et $\mathrm{al}^{49}$ reported on the treatment of a cohort of eight patients with refractory diabetic wounds, in whom bone marrow-derived cells were injected/applied topically into the wound along with platelets, fibrin glue, and bone marrow-impregnated collagen matrix. Offloading was not discussed. After 4 weeks, the wounds were completely closed in three patients and significantly reduced in the remaining five patients. 


\section{Amniotic Membrane}

Letendre et $\mathrm{al}^{74}$ described the application of Biovance (Celgene Cellular Therapeutics, Morris, New Jersey) is a decellularized, dehydrated human amniotic membrane proposed to have collagen matrix and fibroblastic properties indicated for the management of noninfected partial- and full-thickness wounds. The purpose of this study was to determine healing rates for partial- or full-thickness diabetic foot ulcers treated with Biovance over a 12-week period. 13 patients participated in the study, six patients were considered failure, due to infection requiring them to leave the study and one was lost to follow up. At the completion of the 12-week course, if the wound was taken to complete closure during the 12-week period, it was categorized as an excellent result (group 1). For those that responded to Biovance with a significant decrease in wound size of $50 \%$ to $80 \%$, a fair result was noted (group 2). A wound was considered a failed response (group 3 ) if there was less than $50 \%$ improvement during the trial period. Of the 9 patients who were included in the final data, group 1 consisted of 5 patients (55.5\%), group 2 consisted of 3 patients (33.3\%), and group 3 consisted of 1 patient (11.1\%). No offloading was described.

\section{Cost effectiveness}

Several studies have evaluated the cost effectiveness of treatment with collagen wound dressings. In a retrospective chart study Snyder et $\mathrm{al}^{50}$ reviewed patients receiving home care services, and compared wound healing using sequential therapy consisting of collagen (C)/ORC and C/ ORC/silver versus saline-soaked gauze. Of the 974 patients reviewed, 873 had received $\mathrm{C} / \mathrm{ORC}$ and $\mathrm{C} / \mathrm{ORC} /$ silver, and 101 had received the saline gauze treatment. After 2 months of treatment, $95 \%$ of the $\mathrm{C} / \mathrm{ORC}$ and $\mathrm{C} / \mathrm{ORC} /$ silver-treated wounds had closed at a total cost of $\$ 2145$, compared with $7.2 \%$ of healed wounds in the saline gauzetreated group at a total cost of $\$ 7350$; by 6 months, $43 \%$ of saline-treated wounds had healed at a total cost of $\$ 22,050$. Lázaro-Martínez et al ${ }^{51}$ conducted a retrospective study to analyze cost effectiveness of treatment using results from an earlier, 6-week randomized clinical trial. In this analysis 40 patients with DFU were reviewed. The patients had been randomized to two groups: group $1(\mathrm{n}=20)$ was treated with an C/ORC dressing and group $2(\mathrm{n}=20)$ received the standard protocol. Effectiveness was defined as the percentage of patients whose wounds had healed at the end of the study. The total cost of care (including staff, ancil- lary supplies, dressings, and patient-transport costs), the number of patients needing treatment, the mean cost, the incremental cost, and the average cost effectiveness were analyzed. Treatment effectiveness was $63 \%$ in group 1 and $16 \%$ in group 2 . Incremental cost effectiveness (the amount needed to avoid nonhealing in the control group) was $\$ 683.18$. The average cost effectiveness (total cost/ effectiveness in each group) was $\$ 561.48$ in group 1 versus $\$ 2577.65$ in group 2 .

\section{Limitations of current designs}

There is constant tension between the production of high quality evidence for novel, cost-effective, wound care technology dressings and the generalizability of these studies (and their utility for wound care practitioners).${ }^{14}$ For example, despite the literature describing highest DFU healing rates and lowest times to heal associated with use of total contact casts, these are rarely used in clinical practice. In a survey of over 900 US wound care centers, Wu and colleagues ${ }^{52}$ found $<2 \%$ of practices used total contact casts in the treatment of the majority of their DFU patients. Several other authors have pointed out the discrepancies between patient populations studied in DFU studies versus those treated in clinical practice. ${ }^{4,5,14,18,53}$ As Boulton and Armstrong point out, ${ }^{18}$ most DFUs will heal when offloading is used and ischemia and infection are treated. Yet, ischemia and infection are either excluded or causes for censoring in DFU trials despite being highly prevalent conditions in clinical practice. For example, large cohort studies have suggested a prevalence of clinically infected DFUs in $58 \%-61 \%$ of patients; ${ }^{4,5}$ and up to $49 \%$ of patients having peripheral arterial disease. Standardized offloading was only sporadically described in the studies we reported in this review. When removable cast walkers were used in other DFU trials, they were worn a scant $28 \%$ of the time..$^{54}$

Several study limitations emerged from this review. We found several study designs suffered from a small formal number of study participants, lack of standard healing time, lack of standard duration of study protocol, variations of outcomes measures (for eg, complete healing vs 100\% epithelialization vs wound size reduction), variation in the size and location of wounds, and lack of standardization for offloading. Authors' use of variable (or no) wound classification systems makes it difficult to determine wound baselines that are needed for comparisons of outcomes. Patients lost to follow up and high dropout rates may be inherent to this at-risk patient population, but also contributes to the weakness of these studies. Most 
studies failed to utilize or did not describe randomization in study protocol (Table 1). Wounds with infection were excluded but studies did not discuss bioburden and colonization which may have factored in wound healing delay. The average control group healing of $29 \%$ healing (weighted mean $11 \%$ ) is below the $24 \%$ reported in a meta-analysis of control group healing for DFU. ${ }^{19}$ Exclusion of patients with diabetes and significant comorbidities such as renal failure, ischemia, sickle cell, tobacco abuse, and steroid dependency may improve study outcomes ${ }^{53}$ but diminish the potential to improve wound care and wound care products by not focusing on the most vulnerable population.

\section{Future work: for weighing the microbiome/biofilm perspective vs balancing MMPs and extracellular matrix formation. The race to prevent diabetic foot infection (DFI) vs complete epithelialization: are they mutually exclusive?}

Both culture-dependent and culture-independent analyses have demonstrated that diabetic foot ulcers are colonized with a diverse consortium of bacterial species. ${ }^{55-58}$ The microbial population present can vary widely from individual to individual and within the microenvironments of the wound. How bacterial colonization influences the healing of diabetic foot ulcers is not clear, but it is thought that the presence of bacteria likely promotes a stage of chronic inflammation that may inhibit efficient wound healing. For example, bacteria present in a DFU can induce prolonged elevation of proinflammatory cytokines, and increased levels of MMP and oxygen free radicals along with decreased levels of their tissue inhibitors and decreased production of growth factors. ${ }^{59-62}$ Though inflammation is a normal part of the wound healing process, the presence of bacteria can cause the inflammatory response to be too prolonged or excessive and therefore extend the repair process. Thus the management of the microbial bioburden should be recognized as an important aspect of wound management. Wound cleansing and debridement physically remove microbes and their secreted products from the wound. In addition the removal of devitalized tissue likely reduces an important nutrient source of the microbes and therefore reduce the microbial bioburden ${ }^{63}$ Several studies suggest that bioburden is a barrier to healing, and research that specifically targets wound bacteria populations has been promising. ${ }^{64-66}$
The bacteria residing in DFUs are difficult to eradicate, and emerging evidence suggests that bacteria colonizing DFUs exist in a highly persistent "biofilm" state. ${ }^{67,68}$ Biofilms are groups of microbial cells that are attached to a surface and encased in an extracellular polymeric matrix. Bacteria that reside within biofilms are highly resistant to antimicrobial chemotherapies and the host immune system. Thus one of the most successful strategies for the management of biofilm-related infections is the physical removal of the biofilm (as is done with frequent debridement of diabetic foot ulcers).

How collagen-based wound dressings influence the microbial population in DFUs and biofilm development has not been examined. We hypothesize that the way in which collagen dressings influence the wound environment will also alter the microbial species present and their physiology in DFUs. Collagen based-dressings have been shown to inactivate potentially harmful factors such as proteases, oxygen free radicals, and excess metal ions present in DFUs. ${ }^{2} S$. aureus secretes several extracellular proteases, including the V8 serine protease, metalloprotease aureolysin, and cysteine proteinases (staphopain A and staphopain B) ${ }^{69,70}$ Several of these S. aureus proteases possess collagenolytic activity and are implicated in tissue destruction and interference with wound healing. It is possible that in addition to inhibiting MMP protease activity, collagen dressings inhibit the activity of bacterial proteases or provide an abundant alternative substrate that sequesters proteases from the healing wound.

The production of extracellular proteases has been shown to inhibit biofilm development in several bacterial species including $S$. aureus. ${ }^{71}$ In $S$. aureus, deletion of the genes encoding proteases resulted in a significant increase in biofilm formation and thus resistance to antimicrobials. In addition, protease inhibitors have been shown to promote $S$. aureus biofilm formation under environmental conditions that normally accelerate biofilm disassembly ${ }^{71-73}$ Similarly, mutations that lead to strong upregulation of the extracellular proteases, such as sarA and sigB deficiencies, appear to lock $S$. aureus into a planktonic state ${ }^{73}$ lending further support to the inverse correlation between protease expression and biofilm formation. Future work is needed to determine how collagen dressings influence the microbial ecology of DFUs, the activity of microbial tissue-degrading enzymes, and biofilm development in DFUs.

\section{Conclusion}

There is no evidence to support that collagen products should replace the gold standard of diabetic wound man- 
agement, which includes etiology identification, infection management, securement of an adequate vascular supply, regular debridement of nonviable tissue, and offloading. However, despite the limited studies, and the need for improved study designs and increased number of randomized controlled trials, wound dressings containing collagen do appear to have some benefit in the treatment diabetic foot ulcers and should be carefully considered by clinicians that manage wounds. There has not been sufficient evidence to prove the superiority of a particular collagen biological source or combination. A critical pitfall is that the current studies fail to illustrate the necessity for combining collagen-based products with offloading to achieve healing. Future work should further consider the inclusion of biofilm activity and the potential enhancement of extracellular targets. Finally, in order for wound care to advance beyond the current state, the most vulnerable patient populations must also be targeted to better reflect current practice.

\section{Disclosure}

The authors report no conflicts of interest in this work.

\section{References}

1. Landsman A, Taft D, Riemer K. The role of collagen bioscaffolds, foamed collagen, and living skin equivalents in wound healing. Clin Podiatr. Med Surg. 2009;26(4):525-533.

2. Cullen B, Watt PW, Lundqvist C, et al. The role of oxidised regenerated cellulose/collagen in chronic wound repair and its potential mechanism of action. Int J Biochem Cell Biol. 2002;34(12):1544-1556.

3. Mustoe TA, O’Shaughnessy K, Kloeters O. Chronic wound pathogenesis and current treatment strategies: a unifying hypothesis. Plast Reconstr Surg. 2006;117(Suppl 7):S35-S41.

4. Lavery LA, Armstrong DG, Murdoch DP, Peters EJ, Lipsky BA. Validation of the Infectious Diseases Society of America's diabetic foot infection classification system. Clin Infect Dis. 2007;44(4):562-565.

5. Prompers L, Huijberts M, Apelqvist J, et al. High prevalence of ischaemia, infection and serious comorbidity in patients with diabetic foot disease in Europe. Baseline results from the Eurodiale study. Diabetologia. 2007;50(1):18-25.

6. Patti J, Boles JO, Höök M. Identification and biochemical characterization of the ligand binding domain of the collagen adhesin from Staphylococcus aureus. Biochemistry. 1993;32(42):11428-11435.

7. Rich RL, Kreikemeyer B, Owens RT, et al. Ace is a collagen-binding MSCRAMM from Enterococcus faecalis. J Biol Chem. 1999;274 (38):26939-26945.

8. Lannergård, J, Frykberg L, Guss B. CNE, a collagen-binding protein of Streptococcus equi. FEMS Microbiol Lett. 2003;222(1):69-74.

9. Patti J, Allen BL, McGavin MJ, Höök M. MSCRAMM-mediated adherence of microorganisms to host tissues. Annu Rev Microbiol. 1994;48:585-617.

10. Hienz S, Schennings T, Heimdahl A, Flock JI. Collagen binding of Staphylococcus aureus is a virulence factor in experimental endocarditis. J Infect Dis. 1996;174(1):83-88.

11. Mamo W, Fröman G, Muller HP. Protection induced in mice vaccinated with recombinant collagen-binding protein $(\mathrm{CnBP})$ and alpha-toxoid against intramammary infection with Staphylococcus aureus. Microbiol Immunol. 2000;44(5):381-384.
12. Rhem MN, Lech EM, Patti JM, et al. The collagen-binding adhesin is a virulence factor in Staphylococcus aureus keratitis. Infect Immun. 2000;68(6):3776-3779.

13. Elasri MO, Thoma JR, Skinner RA, et al. Staphylococcus aureus collagen adhesin contributes to the pathogenesis of osteomyelitis. Bone. 2002;30(1):275-280.

14. Gottrup F. Controversies in performing a randomized control trial and a systemic review. Wound Repair Regen. 2012;20(4):447-448.

15. Hinchliffe RJ, Valk GD, Apelqvist J, et al. A systematic review of the effectiveness of interventions to enhance the healing of chronic ulcers of the foot in diabetes. Diabetes Metab Res Rev. 2008;24 Suppl 1:S119-S144.

16. Game FL, Hinchliffe RJ, Apelqvist J, et al. A systematic review of interventions to enhance the healing of chronic ulcers of the foot in diabetes. Diabetes Metab Res Rev. 2012;28 Suppl 1:S119-S141.

17. Gottrup F, Apelqvist J, Price P; for European Wound Management Association Patient Outcome Group. Outcomes in controlled and comparative studies on non-healing wounds: recommendations to improve the quality of evidence in wound management. J Wound Care. 2010;19(6):237-268.

18. Boulton AJ, Armstrong DG. Trials in neuropathic diabetic foot ulceration: time for a paradigm shift? Diabetes Care. 2003;26(9):2689-2690.

19. Margolis DJ, Kantor J, Berlin JA. Healing of diabetic neuropathic foot ulcers receiving standard treatment. A meta-analysis. Diabetes Care. 1999;22(5):692-695.

20. Brem H, Balledux J, Bloom T, Kerstein MD, Hollier L. Healing of diabetic foot ulcers and pressure ulcers with human skin equivalent: a new paradigm in wound healing. Arch Surg. 2000;135(6):627-634.

21. Edmonds M; for European and Australian Apligraf Diabetic Foot Ulcer Study Group. Apligraf in the treatment of neuropathic diabetic foot ulcers. Int J Low Extrem Wounds. 2009;8(1):11-18.

22. Sams HH, Chen J, King LE. Graftskin treatment of difficult to heal diabetic foot ulcers: one center's experience. Dermatol Surg. 2002;28(8):698-703.

23. Veves A, Falanga V, Armstrong DG, Sabolinski ML; for Apligraf Diabetic Foot Ulcer Study. Graftskin, a human skin equivalent, is effective in the management of noninfected neuropathic diabetic foot ulcers: a prospective randomized multicenter clinical trial. Diabetes Care. 2001;24(2):290-295.

24. Brem H, Young J, Tomic-Canic M, Isaacs C, Erlich HP. Clinical efficacy and mechanism of bilayered living human skin equivalent (HSE) in treatment of diabetic foot ulcers. Surg Technol Int. 2003;11:23-31.

25. Steinberg JS, Edmonds M, Hurley DP Jr, King WN. Confirmatory data from EU study supports Apligraf for the treatment of neuropathic diabetic foot ulcers. J Am Podiatr Med Assoc. 2010;100(1):73-77.

26. Naughton G, Mansbridge J, Gentzkow G. A metabolically active human dermal replacement for the treatment of diabetic foot ulcers. Artif Organs. 1997;21(11):1203-1210.

27. Gentzkow GD, Iwasaki, SD, Hershon KS, et al. Use of dermagraft, a cultured human dermis, to treat diabetic foot ulcers. Diabetes Care. 1996;19(4):350-354.

28. Kashefsky HE. Outcomes of total contact casting combined with dermagraft in the treatment of 15 consecutive diabetic foot ulcers. Wound Repair Regen. 2011;19(2):A31.

29. Brigido SA. The use of an acellular dermal regenerative tissue matrix in the treatment of lower extremity wounds: a prospective 16-week pilot study. Int Wound J. 2006;3(3):181-187.

30. Martin BR, Sangalang M, Wu S, Armstrong DG. Outcomes of allogenic acellular matrix therapy in treatment of diabetic foot wounds: an initial experience. Int Wound J. 2005;2(2):161-165.

31. Landsman A, Roukis TS, DeFonzo DJ, Agnew P, Petranto RD, Surprenant M. Living cells or collagen matrix: Which is more beneficial in the treatment of diabetic foot ulcers? Wounds. 2008;20(5):111-116.

32. Iorio ML, Goldstein J, Adams M, Steinberg J, Attinger C. Functional limb salvage in the diabetic patient: the use of a collagen bilayer matrix and risk factors for amputation. Plast Reconstr Surg. 2011;127(1): 260-267. 
33. Fleischli JG, Laughlin TJ, Fleischli JW. Equine pericardium collagen wound dressing in the treatment of the neuropathic diabetic foot wound: a pilot study. J Am Podiatr Med Assoc. 2009;99(4):301-305.

34. Clerici G, Caminiti M, Curci V, Quarantiello A, Faglia E. The use of a dermal substitute to preserve maximal foot length in diabetic foot wounds with tendon and bone exposure following urgent surgical debridement for acute infection. Int Wound J. 2010;7(3):176-183.

35. Liao HC, Huang HS, Huang MJ, Chen CC. Preliminary experience with growth factor and porcine graft-young collagenous wettable membrane in the treatment of chronic diabetic ulcer. Changgeng Yi Xue Za Zhi. 1991;14(2):89-94.

36. Parsons D, Bowler PG, Myles V, Jones S. Silver antimicrobial dressings in wound management: a comparison of antibacterial, physical, and chemical characteristic. Wounds. 2005;17(8):222-232.

37. Chaw KC, Manimaran M, Tay FE. Role of silver ions in destabilization of intermolecular adhesion forces measured by atomic force microscopy in Staphylococcus epidermidis biofilms. Antimicrob Agents Chemother. 2005;49(12):4853-4859.

38. Kostenko V, Lyczak J, Turner K, Martinuzzi RJ. Impact of silvercontaining wound dressings on bacterial biofilm viability and susceptibility to antibiotics during prolonged treatment. Antimicrob Agents Chemotherapy. 2010;54(12):5120-5131.

39. Thorn RM, Austin AJ, Greenman J, Wilkins JP, Davies PJ. In vitro comparison of antimicrobial activity of iodine and silver dressings against biofilms. J Wound Care. 2009;18(8):343-346.

40. Percival SL, Bowler P, Woods EJ. Assessing the effect of an antimicrobial wound dressing on biofilms. Wound Repair Regen. 2008;16(1):52-57.

41. Gottrup F, et al. Collagen/ORC/silver treatment of diabetic foot ulcers: A randomised controlled trial. Wound Repair Regen. 2011;19(2):A24.

42. Ulrich D, Smeets R, Unglaub F, Wöltje M, Pallua N. Effect of oxidized regenerated cellulose/collagen matrix on proteases in wound exudate of patients with diabetic foot ulcers. $J$ Wound Ostomy Continence Nurs. 2011;38(5):522-528.

43. Donaghue VM, Chrzan JS, Rosenblum BI, Giurini JM, Habershaw GM, Veves A. Evaluation of a collagen-alginate wound dressing in the management of diabetic foot ulcers. Adv Wound Care. 1998;11(3): 114-119.

44. Lobmann R, Zemlin C, Motzkau M, Reschke K, Lehnert H. Expression of matrix metalloproteinases and growth factors in diabetic foot wounds treated with a protease absorbent dressing. J Diabetes Complications. 2006;20(5):329-335.

45. Motzkau M, Tautenhahn J, Lehnert H, Lobmann R. Expression of matrix-metalloproteases in the fluid of chronic diabetic foot wounds treated with a protease absorbent dressing. Exp Clin Endocrinol Diabetes. 2011;119(5):286-290.

46. Veves A, Sheehan P, Pham HT. A randomized, controlled trial of Promogran (a collagen/oxidized regenerated cellulose dressing) vs standard treatment in the management of diabetic foot ulcers. Arch Surg. 2002;137(7):822-827.

47. Marston WA, Usala A, Hills RS, Mendes R, Minsley MA. Initial report of the use of an injectable porcine collagen-derived matrix to stimulate healing of diabetic foot wounds in humans. Wound Repair Regen. 2005;13(3):243-247.

48. Blume P, Driver VR, Tallis AJ, et al. Formulated collagen gel accelerates healing rate immediately after application in patients with diabetic neuropathic foot ulcers. Wound Repair Regen. 2011;19(3): 302-308.

49. Ravari H, Hamidi-Almadari D, Salimifar M, Bonakdaran S, Parizadeh MR, Koliakos G. Treatment of non-healing wounds with autologous bone marrow cells, platelets, fibrin glue and collagen matrix. Cytotherapy. 2011;13(6):705-711.

50. Snyder RJ, Richter D, Hill ME. A retrospective study of sequential therapy with advanced wound care products versus saline gauze dressings: comparing healing and cost. Ostomy Wound Manage. 2010; 56 Suppl 11A:S9-S15.
51. Lázaro-Martinez JL, Aragón-Sánchez FJ, Garcia-Morales E, BeneitMontesinos JV, González-Jurado M. A retrospective analysis of the cost-effectiveness of a collagen/oxidized regenerated cellulose dressing in the treatment of neuropathic diabetic foot ulcers. Ostomy Wound Manage. 2010;56 Suppl 11A:S4-S8.

52. Wu SC, Jensen JL, Weber AK, Robinson DE, Armstrong DG. Use of pressure offloading devices in diabetic foot ulcers: do we practice what we preach? Diabetes Care. 2008;31(11):2118-2119.

53. Fife C. Wound care in the 21 st century. In: Sancha A, editor. US Surgery. 2007. Touch Briefing; 2007: 63-64. Available from: http://www. touchbriefings.com/pdf/2742/fife.pdf. Accessed August 6, 2012.

54. Armstrong DG, Lavery LA, Kimbriel HR, Nixon BP, Boulton AJ. Activity patterns of patients with diabetic foot ulceration: patients with active ulceration may not adhere to a standard pressure off-loading regimen. Diabetes Care. 2003;26(9):2595-2597.

55. Dowd SE, Wolcott RD, Sun Y, McKeehan T, Smith E, Rhoads D. Polymicrobial nature of chronic diabetic foot ulcer biofilm infections determined using bacterial tag encoded FLX amplicon pyrosequencing (bTEFAP). PLoS One. 2008;3(10):e3326.

56. Gontcharova V, Youn E, Sun Y, Wolcott RD, Dowd SE. A comparison of bacterial composition in diabetic ulcers and contralateral intact skin. Open Microbiol J. 2010;4:8-19.

57. Viswanathan V, Jasmine JJ, Snehalatha C, Ramachandran A. Prevalence of pathogens in diabetic foot infection in South Indian type 2 diabetic patients. J Assoc Physicians India. 2002;50:1013-1016.

58. Wheat LJ, Allen SD, Henry M, et al. Diabetic foot infections. Bacteriologic analysis. Arch Intern Med.1986;146(10):1935-1940.

59. Tarnuzzer R, Schultz GS. Biochemical analysis of acute and chronic wound environments. Wound Repair Regen. 1996;4(3):321-325.

60. Robson MC, Stenberg BD, Heggers JP. Would healing alterations caused by infection. Clin Plast Surg. 1990;17(3):17:485-492.

61. Ladwig GP, Robson MC, Liu R, Kuhn MA, Muir DF, Schultz GS. Ratios of activated matrix metalloprotease-9 to tissue inhibitor of matrix metalloproteinase- 1 in wound fluids are inversely correlated with healing of pressure ulcers. Wound Repair Regen. 2002;10(1):26-37.

62. Bucknall T. The effect of local infection upon wound healing: an experimental study. Br J Surg. 1980;67(12):851-855.

63. McGuckin M, Goldman R, Bolton L, Salcido R. The clinical relevance of microbiology in acute and chronic wounds. Adv Skin Wound Care. 2003;16(1):12-25.

64. Dowd SE, Wolcott RD, Kennedy J, Jones C, Cox SB. Molecular diagnostics and personalised medicine in wound care: assessment of outcomes. $J$ Wound Care. 2011;20(5):232, 234-239.

65. Wolcott RD, Cox SB, Dowd SE. Healing and healing rates of chronic wounds in the age of molecular pathogen diagnostics. J Wound Care. 2010;19(7):272-278, 280-281.

66. Wolcott RD, Rumbaugh KP, James G, et al. Biofilm maturity studies indicate sharp debridement opens a time- dependent therapeutic window. J Wound Care. 2010;19(8):320-328.

67. James GA, Swogger E, Wolcott R, et al. Biofilms in chronic wounds. Wound Repair Regen. 2008;16(1):37-44.

68. Davis SC, Ricotti C, Cazzaniga A, Welsh E, Eaglstein WH, Mertz PM. Microscopic and physiologic evidence for biofilm-associated wound colonization in vivo. Wound Repair Regen. 2008;16(1):23-29.

69. Potempa J, Pike RN. Corruption of innate immunity by bacterial proteases. J Innate Immun. 2009;1(2):70-87.

70. Massimi I, Park E, Rice K, Muller-Esterl W, Sauder D, McGavin MJ. Identification of a novel maturation mechanism and restricted substrate specificity for the SspB cysteine protease of Staphylococcus aureus. J Biol Chem. 2002;277(44):41770-41777.

71. Boles BR, Horswill AR. Agr-mediated dispersal of Staphylococcus aureus biofilms. PLoS Pathog. 2008;4(4):e1000053.

72. Boles BR, Thoendel M, Roth AJ, Horswill AR. Identification of genes involved in polysaccharide-independent Staphylococcus aureus biofilm formation. PLoS One. 2010;5(4):e10146. 
73. Lauderdale KJ, Boles BR, Cheung AL, Horswill AR. Interconnections between Sigma B, agr, and proteolytic activity in Staphylococcus aureus biofilm maturation. Infect. Immun. 2009;77(4):1623-1635.

74. Letendre S, LaPorta G, O’Donnell E, Dempsey J, Leonard K. Pilot Trial of Biovance Collagen-Based Wound Covering for Diabetic Ulcers. Advances in Skin \& Wound Care. 2009; 22(4):161-166.
75. Mulder G, Tallis A, Marshall V, et al. Treatment of nonhealing diabetic foot ulcers with a platelet-derived growth factor gene-activated matrix (GAM501): Results of a Phase 1/2 trial. Wound Rep Reg. 2009; 17: 772-779.

Diabetes, Metabolic Syndrome and Obesity: Targets and Therapy

\section{Publish your work in this journal}

Diabetes, Metabolic Syndrome and Obesity: Targets and Therapy is an international, peer-reviewed open-access journal committed to the rapid publication of the latest laboratory and clinical findings in the fields of diabetes, metabolic syndrome and obesity research. Original research, review, case reports, hypothesis formation, expert opinion and commentaries are all considered for publication. The manuscript management system is completely online and includes a very quick and fair peer-review system, which is all easy to use. Visit http://www.dovepress.com/testimonials.php to read real quotes from published authors.

Submit your manuscript here: http://www.dovepress.com/diabetes-metabolic-syndrome-and-obesity-targets-and-therapy-journal 